\title{
REGULATION OF RADIO FREQUENCY SPECTRUM AND ITS IMPLEMENTATION CHALLENGES IN THE PERSPECTIVE OF INTERNATIONAL LAW
}

\author{
Jean Claude Geofrey Mahoro and Agus Pramono \\ Faculty of Law, Diponegoro University \\ gmahoro88@gmail.com
}

\begin{abstract}
The radio frequency spectrum is a limited natural resource, which is very important and strategic in the operation of telecommunications. Considering that it is a limited natural resource, its management is regulated internationally by the International Telecommunication Union (ITU), in which details are set out in the radio regulations (RR) as an integral part of the ITU Convention. The study is based on applicable legal regulations and is supported by literature studies. The results of the study indicate that the regulation of the radio frequency spectrum is based on radio regulations, international agreements within the ITU through the World Radio communication Conference forum. The implications of regulating the use of the radio frequency spectrum always take into account the general public needs for the dynamics of the progress in telecommunications technology, of which implementation of its utilisation rests in the principle of fairness and equity between regions, and efficiency. Therefore, all policies made are directed at creating a market balance, ensuring fair competition between telecommunication operators as a potential to prevent market dominance, as well as protecting consumers.
\end{abstract}

Keywords: Regulation; Radio Frequency; Spectrum; International Law

\section{Introduction}

In using frequency bands for radio services, members shall bear in mind that radio frequencies and any associated orbits, including the geostationary -satellite orbit are limited natural resources and that they must be used rationally, efficiently, and economically, in conformity with the provisions of these regulation, so that countries or groups of countries may have equitable access to those orbits and frequencies, taking into account the special needs of the developing countries and the geographical situation of particular countries. ${ }^{1}$

Contemporarily, technology has taken a significant advance in all aspects of life. With sophisticated means, people from everywhere can have access to voices and videos from live events and can even make their archives for unlimited future uses. For these activities to happen, the radio frequency (RF) spectrum plays an incredible role. The RF spectrum is a natural resource, which intervenes in any wireless communication. As there is an increase of the terrestrial and space-users of this limited resource, it leads to congestion resulting in unintentional radio frequency interference (RFI) also the space weather itself can also cause the RFI $^{2}$. However, this resource can be intentionally interfered by jammers' activities.

\footnotetext{
${ }^{1}$ See the preamble of Radio Regulations, 2016, 0.3

${ }^{2}$ Brian Weeden, "Radio Frequency Spectrum, Interference and Satellites Fact Sheet," 2013, 1-4, www.swfound.org.
} 
Historically, it was for the first time when Marconi established a practical radio system in 1895 that was able to transmit the radio signals in a distance of two (2) kilometres. Marconi continued with his experiment in radiotelegraph system and, by 1901, it was possible to transmit the radio signals across the distance of 1,700 miles $^{3}$. It was a great advent in technology, although the capacity was only to transmit telegraphic codes. Since 1906, the time of which Reginald Fessenden accomplished the first radio communication, people were able to listen to human speeches over miles. By the time the radio was no longer limited to telegraphic codes ${ }^{4}$.

A wireless communication technology tremendously developed radio broadcasting. In the same year, an American electrical engineer Lee De Forest invented the first electronic amplifying device (vacuum triode) which played a crucial role as it made possible the radio broadcasting by amplitude modulation $(\mathrm{AM})^{5}$. With this technology, Armstrong introduced frequency modulation (FM) in the $1930 \mathrm{~s}^{6}$. Both $\mathrm{AM}$ and $\mathrm{FM}$ are the means of carrying information in the radio broadcasting system without wires. With the RF wireless systems, an introduction of television, one- and two-way radio, radar, and cellular mobile radios, and cellular mobile telephone, as well as all other kinds of communication available on the globe became possible.

The following discussion will study the regulation of the radio frequency spectrum and the implication of regulating the use of the radiofrequency spectrum.

\section{Research Method}

The present research method was based on the current radio regulations as well as the literature review.

\section{Results and Discussion}

\subsection{Regulation of the Radio Frequency Spectrum}

The Radio frequency is a part of the electromagnetic (EM) spectrum. The latter ranges from very high frequency, short wavelength radiation such as x-rays through very low frequency and long wavelength radiation such as radio waves. Among other EM spectrum, humans can

\footnotetext{
${ }^{3}$ Okechukwu Ugweje, Radio Frequency and Wireless Communications (The University of Akron, 2017), https://doi.org/10.1002/047148296X.tie151.

${ }^{4}$ Ugweje.

${ }^{5}$ Physics and Radio-Electronics, "Vacuum Triode," n.d., http://www.physics-and-radio-electronics.com/electronicdevices-and-circuits/vacuum-tubes/vacuumtriode.html.

${ }^{6}$ Ugweje, Radio Frequency and Wireless Communications.
} 
only detect the light ${ }^{7}$. The atmosphere of the Earth absorbs a big part of the EM spectrum, which may significantly diminish, and even blocks the frequencies. Nevertheless, it cannot absorb shorter radio waves usable in the transmissions from space to ground and vice-versa. Moreover, the pollution of the spectrum can occur due to these challenges, and others that are under the following discussion. Thus, a serious issue cannot be easily addressed ${ }^{8}$.

The RF is identified by frequency (Hertz or $\mathrm{Hz}$ ) or wavelength (meters). Both terms reverse one another since the frequency goes up the wavelength goes down and vice-versa ${ }^{9}$. The measurement of RF signals is often in Watts. In addition, a band known as a specific part of the $\mathrm{RF}$ spectrum is always designated to a certain name. For example, radio broadcasting uses amplitude modulation (AM) or frequency modulation (FM).The two are the ways of broadcasting radio signals and transmitting the information in the form of waves ${ }^{10}$.

Electromagnetic fields are from natural and synthetic sources. They are characterised by the wavelength and frequency (measured in hertz $(\mathrm{Hz})$ ). All mobile phones and other wireless technologies including but not limited to mobile phone, tablets, laptops, television, and radio, are sources of electromagnetic fields ${ }^{11}$. Thus, the electromagnetic spectrum includes all frequencies of electromagnetic fields. The RF's measurement is $\mathrm{Hz}$ (hertz), which indicates a number of cycles per second upon transmission of a radio signal. The RF is an electromagnetic invisible to the human eye. Technically, one Hz (hertz) equals one cycle per second (cps). Instead, the RF is a measurement indicating the fluctuation rate of electromagnetic radio waves or electromagnetic radiation spectrum of frequencies ranging from $300 \mathrm{GHz}$ to $9 \mathrm{kHz}^{12}$. The wireless radio frequency is an electromagnetic wave frequency ranging between $3 \mathrm{kHz}$ and $300 \mathrm{GHz}$; this includes those frequencies used for radar signals. Furthermore, the microwaves are radio wave with higher frequencies ${ }^{13}$. Eventually, several wireless communications use the radiofrequency field in connection with transmitters and antennas located in different places ${ }^{14}$.

\footnotetext{
7“Mobile Phones, Radio Frequency Waves and Electromagnetic Fields,” n.d., 10, https://www.scampstudy.org/wpcontent/uploads/2014/05/The-electromagnetic-spectrum1.pdf.

${ }^{8}$ JAMES W. ENGLFS, “CONTROLLIIVG TUE EFFECTS OF RADIO NOISE POLLUTION,” Naval Engeneers Journal, 1971, 76-80.

${ }^{9}$ Weeden, "Radio Frequency Spectrum, Interference and Satellites Fact Sheet."

${ }^{10}$ Diffen LLC, “AM vs. FM,” Diffen .com, 2018, https://www.diffen.com/difference/AM_vs_FM.

11"Mobile Phones, Radio Frequency Waves and Electromagnetic Fields."

${ }^{12}$ Tarun Agarwal, "Wireless Radio Frequency Technology Working and Applications," Edgefxkits International, 2017, https://www.efxkits.com/blog/rf-wireless-radio-frequency-working-application/.

${ }^{13}$ Tarun Agarwal

${ }^{14}$ Tarun Agarwal
} 
The RF modules are in different kinds of sizes and shapes; they can apply small electronic circuit boards. The RF modules include a printed circuit board (PCB), antenna, transmitter or receiver circuit, and a serial interface for communicating with the hosting processor. These RF modules are divided into four (4) types including Transmitter (TX), Receiver (Rx), Transceiver and System on a Chip (SoC) $)^{15}$. The work of these RF modules in the transmission of information is unimaginable. The highest performance of these modules base on different factors. For example, an increase in the power of a transmitter implies an extension of communication distance. That increase of power can lead to a higher electrical power drain on the transmitter device, which results in a decrease operating life of the battery-powered devices and exposes the entire system to the interference with extra RF device ${ }^{16}$.

The wireless communication technology is divided into different categories basing on the distance of communication. These are radio and television broadcasting, radar communication, satellite communication, cellular communication, the global positioning system (GPS), WiFi, Bluetooth, radio frequency identification systems ${ }^{17}$, road toll systems, aeronautical navigation and control, missile tracking, intelligent transport systems, baby alarms, walkie-talkies, radiation therapy, wireless industrial automation, radio astronomy/space research, medical implants, drones, alarms and more ${ }^{18}$. The following part discusses some of these uses due to their potential use of the RF spectrum.

The satellite communication is a wireless technology with significant importance across the globe. It has found widespread use in different situations. Various devices like satellite phone and modems use the satellite technology to communicate directly with the orbiting satellite through radio signals. In addition, the network of a cellular tower with a suitable antenna can make significant broadcasting power where a single frequency band permits many cellular network users to use encrypted radio links ${ }^{19}$. Wi-Fi is another wireless technology, which serves to connect many portable devices in close proximity depending on the router configuration. The light wave transmission is electromagnetic radiation with a wavelength (430 to $750 \mathrm{THz}$ ) ranging between infrared radiations and ultraviolet radiations ${ }^{20}$. These signals cannot penetrate through rain and fog. The radio is another invention that made the use of wireless possible; its transmitter

\footnotetext{
${ }^{15}$ Tarun Agarwal

${ }^{16}$ Tarun Agarwal

${ }^{17}$ Tarun Agarwal, "Different Types of Wireless Communication Technologies."

${ }^{18}$ ERICSSON, 7 Things About Radio Frequency Spectrum.

${ }^{19}$ Tarun Agarwal, "Different Types of Wireless Communication Technologies."

${ }^{20}$ Tarun Agarwal
} 
transmits the data in the form of radio signals to the receiver antenna. Most of the radios broadcast sound through the air as radio waves.

Different advantages and disadvantages of wireless communication can be summarised as follow:

\section{1) Advantages}

a) Quick transmission of information with high speed and accuracy is possible.

b) People can access the internet from anywhere, at any time without cables or wires.

c) Through wireless communication, people can alert emergencies.

d) Communication can reach where wiring is not feasible and costly.

2) Disadvantages

a. An unauthorised person can easily misuse the wireless signals spread through the air.

b. The wireless communication incurs high cost in setting up the infrastructure.

c. The physical constructions, climatic conditions, and other wireless devices can interfere the wireless performance.

Various usages including radio and television broadcasting, Global Positioning System (GPS), satellite broadcasting, Wi-Fi, mobile cellular phone, remote of car keys cannot take place without RF spectrum. However, the mentioned aspects use a small portion of the spectrum in comparison to the government and industrial uses. The latter uses the most significant portion of the spectrum to stabilise the national security, satellite communications, maritime navigations, aviation systems, radars, and radio astronomy. In addition, the most use of spectrum is mobile voice and data, an industry, which grows very fast ${ }^{21}$.

A state is the proprietor of RF spectrum resource within its territory. It can license the organisations in case they want to offer different services such as broadcasting and wireless broadband requiring the RF spectrum in order to operate. The licence always determines the limitation of that use, an object, time and space in order to avoid the harming interferences. For economic reasons, some states opt to liberalise spectrum management in its regulatory system. In doing so, they have to refer to the Radio Regulations and other international legal instruments in order for them not to bring harmful interference with others.

Although the licensing of RF spectrum is conducted at the national level, the radio waves cross national borders, which requires the management to be international that can even make the international mobile calls easier. Among other sectors of ITU, the radio communication ensures

\footnotetext{
${ }^{21}$ GSMA, “Spectrum Handbook,” no. December (2011): 1-20, https://www.gsma.com/spectrum.
} 
the efficiency of Radio Regulations through a four-year based Radio communication Conference. The recent one (WRC-2015) was convened in 2015 to address challenges risen in the field and update the standards of allocating new RF spectrum. The WRC-15 allocated new spectrum to the mobile industry. It set a number of frequency bands available for IMT in three regions, Region 1 (EMEA), Region 2 (Americas) and Region 3 (APAC), of the globe for the enhancement of MIT and Long-Term Evolution (LTE), improvement of rural areas and boosting market opportunities. Finally, the WRC-15 also approved an agenda for WRC-19 to study bands above $24 \mathrm{GHz}$ for $5 \mathrm{G}$ mobile services. The following are six (6) Regional Groups of which their draft proposals, the subjects of assessment in the WRC conference:

(1) Asia Pacific Telecommunity which covers the Asian and Pacific regions,

(2) Arab Spectrum Management Group which covers the Arab states in the Middle East and North Africa,

(3) African Telecom Union which covers all of the administrations on the African continent,

(4) European Conference of Postal and Telecommunications Administrations (CEPT) which is composed of 48 member administrations including all of the EU countries, Russia and Turkey,

(5) Inter-American Telecommunications Commission (CITEL) which covers the Americas and the Caribbean, and

(6) Regional Commonwealth in the Field of Communications (RCC) which covers the Russian Commonwealth of the Independent States and the Baltic states under observatory status.

The Intentional Radio Frequency Interference (RFI) to RF communication may happen in many cases. Other RF sources and natural events, for example, for some frequencies such as ' $\mathrm{Ku}$ ' and ' $\mathrm{Ka}$ ' bands can be disrupted by the heavy rain, snow or weather in general ${ }^{22}$. This makes the RF have no perfect desirability. The most powerful signal can jam the weakest one. This occurs in the GEO region when the satellite drifts another transmitting satellite or when its transponders are misconfigured ${ }^{23}$. The RFI may also happen when an antenna of the transmitter on the ground is pointed at the wrong satellite in orbit. Another unintentional RFI can be from interference between signals used in communication with the satellite and these used in different terrestrial networks systems ${ }^{24}$.

\footnotetext{
${ }^{22}$ Weeden, "Radio Frequency Spectrum , Interference and Satellites Fact Sheet."

${ }^{23}$ Weeden

${ }^{24}$ Weeden 
Article 15 of the Radio Regulation prohibits all kinds of interference from radio stations including carrying out unnecessary transmissions of unidentified, false, misleading or superfluous signals except those provided under Article $19^{25}$. In contrast, due to the large extent use of satellite in various activities, including state security, intentional RFI is more likely to take place. Different countries have developed technologies to jam or interfere with particular satellite communications. This is a way of country militaries to destabilise or control over their adversary. Then, all of these sorts of jamming have more effects on different systems like Global Positioning System (GPS) because of its low power signals ${ }^{26}$.

\subsection{Legal Implications of the Use of Radio Frequency Spectrum}

International Telecommunication Union is a specialised agency of the United Nations (UN) for information and communication technology (ICT) which underpins every aspect of life currently. Previously, there was the International Telegraph Union, established in 1865, of which the signatories to the International Radiotelegraphy Convention started in 1906. The Union served its purposes with the reliability and affordability of telecommunications during the era ${ }^{27}$. ITU is a single international organisation committed to interconnecting the world in fulfilment of the human right to communication. Within the structure of ITU, the supreme organ is the fouryear based Plenipotentiary Conference, which establishes the overall policies and budget. Within its three sectors; radio-communication, standardisation and development, under the global partnership, ITU tries to provide and facilitate the modern communication technologies in an affordable, efficient and safe way. The ITU membership composes of private and public sector; ICT regulators, academic institutions and tech companies. Around 193 members are states, and 700 are tech companies ${ }^{28}$. ITU works with different world-leading standards development organisations in the ICT domain, ETSI is a good example of the globe in the Electromagnetic compatibility and Radio spectrum Matters (ERM) and others ${ }^{29}$. ITU activities empower ICT

\footnotetext{
${ }^{25}$ International Telecommunication Union, "Radio Regulations," in The $R F$ in RFID (International Telecommunication Union, 2016), 487-97, https://doi.org/10.1016/B978-0-12-394583-9.00020-X.

${ }^{26}$ Weeden, "Radio Frequency Spectrum , Interference and Satellites Fact Sheet."

${ }^{27}$ William D. Horne and Robert M Taylor, "New Waves for New Systems," IEEE Spectrum 32, no. 10 (1995): $72-$ 77, https://doi.org/10.1109/6.464294.

${ }^{28}$ International Telecommunication Union, “About International Telecommunication Union (ITU), " International Telecommunication Union, 2018, https://www.itu.int/en/about/Pages/default.aspx.

${ }^{29}$ ETSI, "EN 302 208-2 - V1.2.1 - Electromagnetic Compatibility and Radio Spectrum Matters (ERM); Radio Frequency Identification Equipment Operating in the Band $865 \mathrm{MHz}$ to $868 \mathrm{MHz}$ with Power Levels up to $2 \mathrm{~W}$; Part 2," $\quad$ Intellectual Property 112008 : https://www.etsi.org/deliver/etsi_en/302200_302299/30220801/01.01.02_40/en_30220801v010102o.pdf.
} 
organisations and academia in providing access to emerging technologies. Who talks of ITU talks of ICT and vice-versa; thus, it is at the heart of the ICT sector. The following are, among other duties, the functions ITU in brief:

(1) Many agreements on technologies take place,

(2) Phone calls and internet access became possible,

(3) The management of RF and GSO spectrum,

(4) The warning system on disasters and emergencies as well as the rebuild after a catastrophe,

(5) Emerging of new technologies,

(6) Issuance of a policy framework on the mobile phone revolution,

(7) Partnership with private and public partners for universal and equitable ICT affordability, and

(8) Empowerment the global community with technology.

In fulfilling its responsibilities, ITU reserves the right to allocate important global resources including RF spectrum and Geostationary Satellite Orbit (GSO) ${ }^{30}$. For the global communication system to get reliable, ITU has a big task. Therefore, the ITU standards, protocols, and international agreements play a vital role in the global telecommunication system.

Any aspect of life requires a regulatory framework for safety use, development, and sustainability. As it is scarce basing on its need, the RF spectrum is an important resource to secure for the best use of technologies, which advances day after day ${ }^{31}$. In addition, the use of this particular resource is also in compromise. Various countries jeopardise it for their interests under the pretext of state security. However, this natural resource is a space resource that would be common for all human kinds. The field of RF is not regulated well. For example, when a satellite of state $\mathbf{A}$ broadcasts in the space above the territory of state $\mathbf{B}$ with a purpose to carry political or cultural messages without the consent of the state B. the latter will try to jam these transmissions to prevent the future broadcasts although jamming is a violation of the ITU Convention. Nevertheless, the International Telecommunication Union (ITU) has no enforcement mechanism of its legal instruments to prevent and punish Jamming. Accordingly, the mechanism of ITU convention implementation is needed.

\footnotetext{
${ }^{30}$ International Telecommunication Union, “About International Telecommunication Union (ITU)."

${ }^{31}$ ERICSSON. "COGNITIVE RADIO NETWORKS: A PRACTICAL PERSPECTIVE Worldwide Trends In Regulation of Secondary Access to White Spaces Using Cognitive Radio." MAZIAR NEKOVEE, BT RESEARCH AND TECHNOLOGY," no. August https://ieeexplore.ieee.org/stamp/stamp.jsp?arnumber=7909902.
} 
The Regional Radio Conference (RRC) on terrestrial broadcasting that held in Geneva in 2004/2006 brought a big change in the field if RF use when countries committed to the move from analogue to digital Television by 2015. This move left a big part of the electromagnetic spectrum for other uses. As Martin Cooper mentioned, a large part of the RF spectrum is underutilised because of the antiquated ideas and the habit. The use of spectrum would depend on the law but scientists and engineers compromised this. After three to four years, lawyers, diplomats, economists, and engineers gather in Radio communication Conference (WRC) to review and amend the Radio Regulations. The way decisions are taken through consensus principle and the unbalanced representation in this Conference leads it not to be fair while accommodating any provision contradicting the interests of the member states. As a result, the conference results are very likely to be ignored because it may put some unrepresented spectrum user groups in unfavourable situations for longer ${ }^{32}$.

Article two (2), Section one of the Radio Regulations states frequency and wavelength bands basing on their progressive numbers. It divides the radio spectrum into nine bands and highlights three ways in which the frequency should be expressed within the Union. These are:

(1) in kilohertz $(\mathrm{kHz})$, up to and including $3000 \mathrm{kHz}$;

(2) in megahertz (MHz), above $3 \mathrm{MHz}$, up to and including $3000 \mathrm{MHz}$;

(3) in gigahertz $(\mathrm{GHz})$, above $3 \mathrm{GHz}$, up to and including $3000 \mathrm{GHz}$.

Nevertheless, the convention allows a departure in case the adherence to these provisions introduces serious difficulties such as these in relation to the notification and registration of frequencies, the lists of frequencies and other related issues.

Table of Frequency Allocations ${ }^{33}$

\begin{tabular}{cccl}
\hline $\begin{array}{c}\text { Band } \\
\text { Number }\end{array}$ & Symbols & $\begin{array}{c}\text { Frequency range (lower limit } \\
\text { exclusive, upper limit inclusive) }\end{array}$ & $\begin{array}{c}\text { Corresponding metric } \\
\text { subdivision }\end{array}$ \\
\hline 4 & VLF & 3 to $30 \mathrm{kHz}$ & Myriametric waves \\
5 & LF & 30 to $300 \mathrm{kHz}$ & Kilometric waves \\
6 & MF & 300 to $3000 \mathrm{kHz}$ & Hectometric waves \\
7 & HF & 3 to $30 \mathrm{MHz}$ & Decametric waves \\
8 & VHF & 30 to $300 \mathrm{MHz}$ & Metric waves \\
\hline
\end{tabular}

\footnotetext{
${ }^{32}$ ERICSSON

${ }^{33}$ International Telecommunication Union, "Radio Regulations."
} 


\begin{tabular}{clll}
\hline 9 & UHF & 300 to $3000 \mathrm{MHz}$ & Decimetric waves \\
10 & SHF & 3 to $30 \mathrm{GHz}$ & Centimetric waves \\
11 & EHF & 30 to $300 \mathrm{GHz}$ & Millimetric waves \\
12 & & 300 to $3000 \mathrm{GHz}$ & Decimillimetric waves \\
\hline
\end{tabular}

NOTE 1: "Band N" ( $\mathrm{N}=$ band number) extends from $0.3 \times 10 \mathrm{~N} \mathrm{~Hz}$ to $3 \times 10 \mathrm{~N} \mathrm{~Hz}$.

NOTE 2: Prefix: $\mathrm{k}=$ kilo (103), $\mathrm{M}=$ mega (106), $\mathrm{G}=$ giga (109).

Article four (4) paragraph one (1) of the Radio Regulation assigns duties to the ITU member states to limit the number of frequencies and spectrum used to the minimum essential in order to satisfy the necessary services. In this light, the ITU recommends the member states to apply for the latest technological advancements. In the following paragraphs, it recalls the assignment of frequencies in accordance to the given Table of Frequency Allocations and other provisions of the Radio Regulations in order to avoid any harmful interferences to services rendered by stations using frequencies. This recommendation would also apply to the new assignment or any change of frequency.

In addition, Article 4 prohibits the administrations of member states to assign any frequency to the station in derogation of both the Table of Frequency Allocations and other provisions of the Radio Regulations. By exception, this can happen on the express of not causing any harmful interference and that it shall not claim protection from harmful interference caused by such station. For resolving the issues of harmful interference, the radio astronomy service was included in radio-communication services. However, the radio astronomy service gets protection from services in other bands only if these services have protected from each other. This is similar to the space research service and the earth exploration-satellite service vis-à- vis different services in other bands. Where a band of frequencies is allocated to different services of the same category in Region or sub-Region, the principle of equality of right to operate applies. The stations of each service in one Region or sub-Region must operate without causing harmful interference to any service of the same or higher category in the other Regions or sub-Regions ${ }^{34}$.

For safety use of the frequency spectrum, the Radio Regulations recommend the ITU member states to set up special measures to ensure their freedom from harmful interference. The member states were also encouraged to reserve frequencies in bands between $5 \mathrm{MHz}$ and 30 $\mathrm{MHz}$ mainly for long-distance communications. An exception to this was reserved to an authorisation as a recourse to the special methods of working provided by the regulations. For

\footnotetext{
${ }^{34}$ ITU, "International Telecommunication Convention," 74 § (2016).
} 
the purpose of communication with the public telegraph and telephone networks, aircraft earth stations are authorised to use frequencies in the bands allocated to the maritime mobile-satellite service via stations such service.

Article 4 of the Radio Regulations is an integral part as it strictly enshrines all possible assignments of the RF spectrum as a scarce resource in a conducive environment, which avoids harmful interferences. By exception to the normal use, which complies to the set standards, the ITU member states were given possibilities although the legal authorisation is a requirement. This is an important part in management of RF spectrum. Thus, any necessary assignment of RF spectrum is highly recommended to the stakeholders in contrast to the one exposing such management at risk of harmful interferences. Furthermore, Article 13 gives an assignment of developing rules of procedure and proposals to resolve inconsistencies encountered in the application of the Radio Regulations to the Radio Regulations Board.

\section{Conclusion}

The ITU Council determines the agenda of the coming WRC in order to review the Radio Regulations. The latter is the international treaty governing the use of the RF spectrum and the geostationary satellite and non-geostationary satellite orbits. The recent WRC conference convened with an expectation of resolving the problems in the management of the RF spectrum in the rapid-changing world. It allocated a new spectrum to the mobile industry for enhancement of MIT and LTE, improvement of rural areas and boosting market opportunities. It also approved the agenda of the WRC-19.

That guaranteeing of successful development of radio communication and implementation of these applications calls for the availability of appropriate interference-free frequency bands, at the national, regional and international levels, in accordance with the Radio Regulation, recommendation, and resolution of the ITU Radio communication Sector (ITU-R).

\section{Recommendations}

ITU has done a great job in regulating the spectrum, although the framework in which the Radio Regulations are enacted may lead to a derogation. Notably, there would be a fair representation and decision-making process in the WRC as its regulations may result in the implementation failure once the interests of some members ignored in the benefits of others. 
The international cooperation is the only solution that could render to the best management of all natural resources, including space resources like RF spectrum. This partnership would be enhanced in an inclusive way, which will not leave anyone behind as everyone deserves to that common property.

\section{References}

Bbc. "The Spectrum and Its Uses," no. September (2006): 24. https://doi.org/10.1002/047148296X.tie151.

Diffen LLC. “AM vs. FM.” Diffen .com, 2018. https://www.diffen.com/difference/AM_vs_FM.

ENGLFS, JAMES W. "CONTROLLIIVG TUE EFFECTS OF RADIO NOISE POLLUTION.” Naval Engeneers Journal, 1971, 76-80.

ERICSSON. 7 Things About Radio Frequency Spectrum, issued 2018.

\section{—. "COGNITIVE RADIO NETWORKS: A PRACTICAL PERSPECTIVE Worldwide} Trends In Regulation of Secondary Access to White Spaces Using Cognitive Radio.” MAZIAR NEKOVEE, BT RESEARCH AND TECHNOLOGY, no. August (2015): 32-40. https://ieeexplore.ieee.org/stamp/stamp.jsp?arnumber=7909902.

ETSI. “EN 302 208-2 - V1.2.1 - Electromagnetic Compatibility and Radio Spectrum Matters (ERM); Radio Frequency Identification Equipment Operating in the Band $865 \mathrm{MHz}$ to 868 MHz with Power Levels up to 2 W; Part 2." Intellectual Property 1 (2008): 1-15. https://www.etsi.org/deliver/etsi_en/302200_302299/30220801/01.01.02_40/en_30220801 v010102o.pdf.

- "Radio Frequency Spectrum Regulation." 2018. https://www.etsi.org/WebSite/document/Technologies/LEAFLETS/Radio Frequency Spectrum_2010_02.pdf.

GSMA. "Spectrum Handbook," no. December (2011): 1-20. https://www.gsma.com/spectrum.

Horne, William D., and Robert M Taylor. "New Waves for New Systems.” IEEE Spectrum 32, no. 10 (1995): 72-77. https://doi.org/10.1109/6.464294.

International Telecommunication Union. "About International Telecommunication Union (ITU)." $\quad$ International $\quad$ Telecommunication 2018. https://www.itu.int/en/about/Pages/default.aspx. Union, 2016. https://doi.org/10.1016/B978-0-12-394583-9.00020-X. 
ITU. International Telecommunication Convention, $74 \S$ (2016).

"Mobile Phones , Radio Frequency Waves and Electromagnetic Fields," n.d., 10. https://www.scampstudy.org/wp-content/uploads/2014/05/The-electromagneticspectrum1.pdf.

NSW Government Telco Authorit. "What Is Spectrum?," 2018. http://telco.nsw.gov.au/content/what-spectrum.

Physics and Radio-Electronics. "Vacuum Triode," n.d. http://www.physics-and-radioelectronics.com/electronic-devices-and-circuits/vacuum-tubes/vacuumtriode.html.

Tarun Agarwal. "Different Types of Wireless Communication Technologies." Edgefxkits International, 2017. https://www.edgefx.in/different-types-wireless-communicationtechnologies/.

—. "Wireless Radio Frequency Technology Working and Applications." Edgefxkits International, 2017. https://www.efxkits.com/blog/rf-wireless-radio-frequency-workingapplication/.

Ugweje, Okechukwu. Radio Frequency and Wireless Communications. The University of Akron, 2017. https://doi.org/10.1002/047148296X.tie151.

Weeden, Brian. "Radio Frequency Spectrum, Interference and Satellites Fact Sheet,”2013, 1-4. www.swfound.org. 